\title{
A Model of Clustering Process in Low Income Economies
}

\author{
Zhaochen Han \\ The O\&M Project Management, Sinoma SCC Project \\ Na Bi WU PO box 67105 \\ AL-HASSA 31928, Kingdom of Saudi Arabia \\ Tel: 96-6-532-741-801Ｅ-mail: hanzhaochen1211@gmail.com
}

\begin{abstract}
Business clusters has been regarded as one sources of competitive advantage. Argument of the advantage developing clusters in low economies has been learned that in developed economies. With such advocacy emerging about the evidence for these in developed world, exploration for the review of the experience in developing economies is required. A model of the development path of business cluster in developing world has been produced. The evaluation of such model in low economies needs to be taken.
\end{abstract}

Keywords: Model, Business cluster, Low economies

\section{Introduction}

The experience of agglomeration and clustering of small scale industry form this of organization have contributed to successful performance of many small businesses in previous studies(Schmitz, 1995, Schmitz \& Nadvi, 1999). More importantly, since the European experience, particularly Italian cases, has adopted to be the main reference resources in studies on clustering in low income economies (Schmitz, 1995). However, Schmitz (1995) claim that it is widely common to be a mismatch between the worldwide consideration on the European experience s and what is actually known about them. He further argues that the European clustering situations have undergone changes since they came to prominence. In reality, since the 1990s, for example, Italian business clusters face many new challenges and they are not performing as well as during the 1970s and 1980s (Whitford, 2001). Generally speaking, a significant difference between low income economies and high income economies appears to be the market niches on which they focus (Wang, 2006). In high income economies, there is the "high road" or "strong competition". High income economies specialize in higher-value niches so these clusters are dynamic and require high levels of innovation and function flexibility and good conditions (Nadvi \& Schmitz, 1994; Schmitz, 1995). Clusters in low economies on the other hand appear mot of them at the market where there are less dynamic and where competitiveness is determined by price, namely, in "low road" or "weak competition". Another remarkable fact which distinguishes business clusters in low income economies form the advanced nations is the abundance of workforce (Schmitz, 1995a).Not surprisingly, the business clusters face two contrasting growth paths between low income and high income economies (Schmitz, 1995,1999).

By means of a highly suggestive theoretical model proposed by Schmitz (1995), which provides an interpretation of cluster development simplifies diversity while claiming to capture key transitions in growth within low income economies(H. Schmitz \& Nadvi, 1999). This model explain why some clusters have capacity to respond to opportunity and crisis and other not (Schmitz, 1999). This model emphasizes to how advantages received by an individual cluster vary with the stage of incipient and more advanced stage of industrialization in low income economies.

\section{Clustering Process in Developing Countries}

In the early stage of industrialization of low income economies, small scalebusinesses face many the growth constraints (Amin, 1994; Schmitz \& Nadvi, 1999). In the paper published in 1982, Schmitz generally classifies the growth constrains into categories: those of an internal nature (entrepreneurship management) and those of external nature (access to resources, exploitation by large scale firms). On the one hand, in term of internal factors, the importance of entrepreneurship in low income economies' industrialization is emphasized by Schmitz (1995). A lack of entrepreneurial and managerial ability is as one of major of growth constraint. In detail, such constraints mainly reflect in the fields of motivation, drive, adaptability; organizational skill; and technical skills (H. Schmitz, 1995). On the other hand, Schmitz $(1995,1999)$ briefly summarizes the growth of constrains of small scale industry deriving from the fields as following 

(a) exploitation;
(b) subcontracting;
(c) access to markets ;
(d) technological gap;
(e) access to raw material;
(f) access to credit; and
(g) government discrimination.

In summary, Schmitz (1995) proposes that access to clusters advantages for individual firms first are able to obtain simply within its geographical reach. Business clusters may simply emerge due to that certain bulky resources are available at certain location only (Sandee \& Rietveld, 2001), to be the advance of buyers as there are likely to be transaction cost reduction if they can products at certain location (Klapwijk, 1997). Also, such kind of unplanned cooperation among small producers may occur when there are sudden financial shortage or when there are rush orders that need extra workforce at a short situation (Schmitz, 1995a). In addition, extended family networks or social tradition are especially important when small businesses are all operating in fixed locations where they have been living for generations. At its most basic level, cooperation within clusters are unplanned (H. Schmitz, 1995). Each business within cluster has equal access of information of the economies of geographic concentration. To some extent, individuals can benefit more from their relationship among firms within clusters basing on joint actions. Such planned action leans upon arrangements among selected participants in clusters. Noticeably, clustering benefits are unevenly distributed owing to their various willingness and ability of businesses to involve in joint action. As a matter of fact, probably the majority of business clusters never engage in joint action.

At outset of a cluster (unplanned action), firms seems to be encouraged information sharing and opportunities for learning new technique and designs (McCormick, 1999). Some firms can benefit directly though market and contracts or indirectly through public good-externalities spillovers types of mechanisms (Ferrero \& Maffioli, 2004). To some extent, being unplanned action, these benefits include human resource pooling, localization economies, access to information, performance benchmarks, and specialized knowledge on technologies and markets, availability of infrastructure and the business environment and complementary products and market access (Ferrero \& Maffioli, 2004).

In low-income economies, the basis of local (generally small ) enterprise is one out of two ways to achieve industrialization (H. Schmitz, 1995). To achieve industrialization, there are two basic elements: the mobilization of unused local resources (financial and human) and the effective use of these resources (Schmitz, 1995). Due to constraints of small-scale businesses, it is impossible for a producer to acquire equipment for the entire production processes. Therefore, one firm is able to specialize in some aspect of the productions process while another may turns form productions to trade in input final products(Schmitz, 1995a). Meanwhile, specialized workshops which can repair and upgrade existing machinery further help to reduce technological discontinuities (Schmitz, 1995). In addition, small amounts of human capital can be made to count (Schmitz, 1999, p.1505). One small business's investment in specialized skill render returns due to other businesses firms have invested in complementary expertise (Schmitz, 1999). Clusters makes easier for the essential changes for the need of industrialization to occur (McCormick, 1999). For example , trader many appear because they heard of the existence of the cluster (McCormick, 1999). Therefore unplanned advantages enables firms to advanced by taking small and calculable risks (Schmitz, 1995). To some extent, unplanned action facilitates the mobilization of financial and workforce, that it breaks down that business activities of small scale enterprises into small riskable steps, that the firm of one create of foundation for the other, that ladders are made which enhance small firm to climb up (Schmitz, 1999).

The external economies (normally related to labour -marketing polling, inter-mediate input effects, technological spillovers and market access (see example McCormick 1999) may promote clusters as long as market, technology ability and organizational form keep stable. In contrast to high income economies where clusters may occure owing to agglomeration economies alone (Schmitz, 1995), agglomeration economies relying on themselves are unable to enhance clusters to ride out significant transformations in products or factor markets (Schmitz, 1999a; H. Schmitz \& Nadvi, 1999).

This stylized growth model proposed two prerequisites to exploit the limits to the potential formation of clusters. One is existence of trade network, another is the existence of effective sanctions and trust (Schmitz \& Nadvi, 1999). Any gap in either of these basic of prerequisites will affect the mobilization of financial and human resources of clusters. A cluster that is restricted in its local markets are likely to experience involutionary rather evolutionary growth (Schmitz \& Nadvi, 1999). A cluster tends to attract traders to reduce to the transaction costs. To some extent, trading networking - a component of personal or economic interaction affects individual performance directly as it generates information on the ability of technologies and marketing (Mobig, 2005).In reality, not all effective trade links to larger 
distant markets exist. For example, in Indonesia where trade networks are highly developed, cluster are not ubiquitous (Weijland, 1994). He concludes in his paper that rural clusters which are well connected to distant markets by traders have higher earnings than those who are not. Similarly, in the areas of East and Southern African countries, poor distribution networks have been accounted to be one of reasons for the comparatively weak development of clusters. Another condition related to clusters emergence and survival is the existence of effective sanctions and trust. Sanctions and trust play an significant role both within clusters and their trade networks (Humphrey \& Schmitz, 1996; Nadvi, 1999b). A deepening specialization leads to a high level of interdependence among cluster firms. From the studies of East Africa, McCormick (1999) emphasizes that enforcement and business collaboration are often stymied by the absence of highly-developed legal system. In poor communities, including small industry clusters, traditional ethic networks play a substantial role in a substantial role of premises on which to operate economic activities, in the entry and emergence of small business clusters (Mobig, 2005). Not surprisingly, thus local information mainly are controlled by the ethic division or family bonds. "Strangers" connect smoothly with such low income communities unless not only they interface successfully interface with the traditional information channels but also they incorporate rightly locally generated information. Based on this situation, traditional social network have been classified into one of limits stymie the development of cluster growth ( Morfessis, 1994).

From the case studies of African clusters, it shows the accumulation of capital and skills remains lows (McCormick, 1998). Similarly, as Schmitz (1999) emphasises that unplanned action are not sufficient and that planned action is the second critical element to explains growth and competitiveness. As a result, a significant transition point should be appeared to consciously pursue joint action. The turning points from the stage of unplanned action to planned action derive significantly from the challenge of liberalization and globalization faced by clusters ( Schmitz \& Nadvi, 1999). Joint action can " promote competitiveness, accelerate innovation and enhance prospects of growth for the clusters as a whole...also improve the ability of the cluster of respond and collectively to exogenous pressures and capitalize on new opportunities" (Nadvi, 1999).

According to Schmitz (1995), a table is proposed as following (see table 1):

Such joint action in low-income economies can be of two types: individual firms cooperating and firms jointing forces in business associations, producer consortia and the like (Schmitz, 1997). For example, sharing equipment can be classified into the item of bilateral action. If firms are taking similar business activities, the cooperation between two firms is horizontal; if they are engage in different links of the production chain, the cooperation is vertical. Multilateral cooperation involves a groups of firms joining together in some kind of sectoral association of pursue common goal.

According to Schmitz $(1995,1997)$ and (Nadvi, 1999a), there are at least four general forms of joint action (Ferrero \& Maffioli, 2004) as following:

--- joint action within vertical linkages, including backward ties and networks with suppliers and subcontractors, and forward ties with traders and buyers

---joint action within bilateral horizontal linkage, between to more local producers. This can be include joint marketing of products, joint product development, and the exchange of know-how and market information.

---joint action within multilateral horizontal linkage among a large number of local producers, particularly through cluster-wide institutions. This include cooperation in business associations and business development service centres.

--- public-private partnerships.

More importantly, in well-developed clusters there may be multilateral institutions raging from trade associations and sale consortia to political lobbies (Albu, 1997). Examples of collectively inspired action may include: opening new market through trade fair; improving local infrastructure, and organizing technical training.

Briefly speaking, four common defining characteristics of joint action are summarized

(1) while unplanned action tend to be cluster-wide, planned action tends to be selective;

(2) greater collaboration tend to be positively associated with improved performance;

(3) In contrast to unplanned action, unplanned action has led to differentiation. In other words, the performance of individuals within the stage of joint action diverges according to their capture of the benefits from planned action.

\subsection{Reflection on the Model}

\section{Public Agency Intervention}

This model does not ignore the role of public agency completely. Schmitz (1995, p.554) argues "governments or government-sponsored institutions cannot create an industrial organization which competes on the basis of collective efficiency". Schmitz(1995) claims that public agency can play an important part in helping industry to expand and innovate once the private initiative has led to a minimum concentration of industrial activity and know-how. Schmitz (1995) pointed out that the emergence of business clusters in European countries was spontaneous. In other words, that 
European industrial districts (clusters) were not result of planned action of a local or regional industrial strategy. To some extent, it seems that clusters in European went through two stages : first, spontaneous emergence and growth, and late public agency intervention growth (Humphrey \& Schmitz, 1996). There are limitations when policy makers in low income nations aim to apply the experience European nations. Institutional polices adopted in European clusters were initially about promoting existing and dynamic clusters of firm to run better, or to respond new challenges (Humphrey \& Schmitz, 1996). Consequently, where clusters with a deep inter-firm division of labour already exist in low income economies, the European experience can be cited directly (Humphrey \& Schmitz, 1996; H. Schmitz \& Nadvi, 1999).

However, the major policy challenge in low income economies is the period of infancy or the absence of linkages features of the successfully business clusters (Humphrey \& Schmitz, 1996). Subsequently, in such situation, public intervention will have to attempt to create the kinds of interaction within clusters. Meanwhile, policies in low income nations will also have to focus on what measures can be applied to small scale industry which are not concentrated together in large, sectorally, specific agglomerations (Humphrey \& Schmitz, 1996).

\section{Value Chain Governance and Globalization}

With the deepening integration of developing countries into global markets, firms in such countries face increasing competitive pressure (Humphrey \& Schmitz, 2002; Schmitz, 1999). Both the cluster and value chain approaches emphasize the importance of upgrading in order to ace increasing competition in global markets (Humphrey \& Schmitz, 2002). Therefore, one of most remarkable development of this model, Schmitz has suggested need to be made since he first proposed the model. He has drawn attention to clusters that failed to make the transition to planned coordination and has linked clusters to value chain governance. From the history of high income nations we know of clusters losing their former competitiveness (Schmitz \& Nadvi, 1999). The unprecedented competitive pressure arising from increasingly globalized product markets make a significant transition point from unplanned action to planned action. In the currently prevailing enthusiasm for local producers to insert themselves into global value chains, lashes of interest between the two sides tend to neglected (H. Schmitz \& Nadvi, 1999). In other words, global competitions bring them together, namely a requirement of joint action. More specifically, a strong case of the benefits of clusters in enhancing low-income-country industrialization has been developed from examples that have adapted the demands of industrialized nations(see Nadvi, 1999; Schmitz, 1999). Such examples have focused on by global development agencies to justify their support to clusters (Humphrey and Schmitz, 1995). Take an empirical case study as the illustration. Nadvi (1999) conducted a deliberated case study on Sialkot, a area with a population of about 660,000, which is a Pakistan's leading centres of manufacturing exports. It's exports are mainly focused on three industrial sectors - namely, sports products, leather garments and stainless-steel surgical instruments. In the past several years, this region has attracted the eyes internationally result in employing child workforce in manufacture of soccer balls. The cluster of surgical-instrument cluster is not free of child workers but quality management, rather than employment conditions, has been its challenged recently. The food and Drug Administration (FDA) of America, for example, restricted imports of surgical instruments from Pakistan in 1994. Due to the America is major exporting market, the decision from the US put the cluster disadvantage. Similarly, such restriction occurred in 1989 as well, and it indicated a worsening situation. To the extent, the 1989's embargo is result in product-quality concerns; the concerns in latter embargo had sped to quality assurance and demands that exporters show evidence of good manufacturing practice. Furthermore, through this case, an account of the crisis is offered to show how cluster participants overcame the restrictions and recovered their overseas markets. At the same time, Nadvi (1999) indicates that the model of organization -cluster facilitated resolution of the crisis in spite of that some weaknesses and shortcomings in the performance of the clusters are recognized. By 1999, according to the estimation of Nadvi (1999), the Sialkot surgical-instrument involve about 300 producers, surrounded by more than 1,500 process specialized subcontractors and about 1,000 other supporting establishments. Furthermore, based on various marketing demands, the cluster comprises two market segments. One concentrates on high-quality products, reusable instruments made with imported raw material and mainly sell to European market; the other producers disposable instruments from locally made raw material form recycled and scrap metal. In the American market, the increasing demands for disposable instruments are the reaction to the rising cost of sterilization and problems of contamination from used instruments. For FDA, the quality of raw material became the first concerns. Fortunately, this was solved by manufacturers by negotiation with the locally based suppliers and successfully addressed in the early 1990s.

However, the FDA suspended exports pending exporters receiving certification that they obtained "good manufacturing practices" in May 1994. By December of that year, a large scale firm in this cluster had received such certification. Most importantly, as evidence of cluster competitiveness, the sectoral association called the Surgical Instrument Manufacturers' Association (SIMA) sought to government support to appoint an American quality-assurance consultant company. Meanwhile, the certificated firm was responsible for providing the training aiming at helping other producers to attain the FDA certification. Consequently, 3 years later, in 199775 manufactures had qualified to export with the total over the following year due to the training programme. Noticeably, the role of sectoral association and crisis can be considered as impetus to improve the inter-firm cooperation to concentrate on quality affairs. In reality, prior to the 
1994 restrictions, communication among buyers and suppliers, and assistances to subcontractor had already frequent on matters associated to issues on organization and quality. After 1994, more concerns are concentrated on quality improvement.

Significantly, during this crisis, subcontracting matters had been regarded as more demanding, especially with respect to the documentation of be completed at a single production stage. A large number of subcontractors, for example, were unaccustomed to new quality-assurance system, and thus, exporters had to help these subcontractors make a major adjustment to their previous production practices. To some extent, the survival of subcontracting suggests recognition of its contribution to the overall functions of this cluster. In addition, producers commenced to reduce the number of subcontractors and to ring some previously out-sourced work in-house. Even many large firms made a substantial cutback in the selection of subcontractors.

To the extent with the relationship with overseas buyers, one significant outcome of import restriction is that the independent certification of producers may mean that buyers estimate less risk in 'arm's length' relationship than before. For example, a powerful buyer can withdraw the technical help a large number of suppliers. At the same time, the purchase volumes could be stable or similar. However, due to the availability of the alternative sources of support, suppliers, thus, their quality-control are cut back. Producers have been eager to widen their market ranges as an assurance of over-dependency on a single market. To some extent, in some situation, producers may be dissatisfied with a single buyer are often required to adapt exclusive supply arrangements without being offering higher prices or lacking opportunities to diversify into high-value products.

Turing to the function of governmental intervention, nonetheless, during the development of this cluster, a public agency intervenes to spread participation in planned action. As can be seen, SIMA's successful acquisition of government funding to help related training enabled cluster producers to attain quality certification. The ability of such sectoral association to seek the support is the result of change in the association's executive committee to be more attention on the interests of small firms in need of training assistance. Otherwise, these firms would have to purchase form large firms. In addition, since as quality certification had widened the choices of suppliers, the relationship between individual buyers and suppliers weaken than previously existed. Unfortunately, its later story is that this cluster failed to upgrade its manufacturing to the point where its producers trade directly with brand-name suppliers. Most of buyers are distributors or wholesalers rather than manufacturers which is due to lower prices and exclusion from potentially significantly sources of technological and manufacturing assistance (Nadvi, 1999).

\section{Conclusion: An Evaluation of the Model}

Gaps and uncertainties lies in the stylized account of business clusters in low income economies beyond he questions already existed. One limitation is, for instance, are reference to the relationship between a specific clusters and its external environment. An absence of evaluation of how specific industry sector and market conditions influence the economies activities, the function of a cluster can be weaken or exaggerated. Furthermore, due to that this model focus on overlook identifying stages of clusters growths, this model to lack differentiation between types of clusters. For example, there are numerous clusters can be classified raw material-based ones. The time raw material run out is the time of disappearance of a cluster.

\section{References}

Amin, A. (1994). The difficult transition from informal economy to Marshallian industrial district. Area, 26(1), 13-24.

Ferrero, L., Maffioli, A. (2004).The interaction between foreign direct investment and small and medium-sized enterprises in Latin America and the Caribbean: a look at regional innovation systems. Inter-American Development Bank, Special Office in Europe, Paris, Working Paper Series, No. 6 A.

Humphrey, J., \& Schmitz, H. (2002). How Does Insertion in Global Value Chains Affect Upgrading in Industrial Clusters?. Regional Studies, 36(9), 1017.

Klapwijk, M. (1997). Rural industry clusters in Central Java, Indonesia: an empirical assessment of their role in rural industrialization. Vrije University Amsterdam

McCormick, D. (1999). African Enterprise Clusters and Industrialization: Theory and Reality. World Development, 27(9), 1531-1551.

Mobig, I. (2005). The evolution of regional packaging machinery clusters in Germany in A. Lagendijk., \& P. Oinas (Eds), Proximity, distance and diversity : issues on economic interaction and local development (pp.129-152). Burlington: Ashgate Publishing company, 153-167.

Morfessis, I. T. (1994). A cluster-analytic approach to identifying and developing state target industries: the case of Ariona. . Economy development review Spring, 33-57. 
Nadvi, K. (1999). 'Facing the New Competition: Business Associations in Developing Country Industrial Clusters', Discussion Paper DP/103/1999, Geneva: International Institute for Labour Studies.

Nadvi, K., \& H. Schmitz. (1994). Industrial clusters in less developed countries : review of experiences and research agenda / by Khalid Nadvi and Hubert Schmitz. IDS discussion paper. No.339. Institute of Development Studies. Brighton.

Sandee, H., \& Rietveld, P. (2001). Upgrading traditional technologies in smll-scale industry clusters: collaboration and innovation adoption in Indonesia. The journal of development studies, 37. No.4, 150-172.

Schmitz, H. (1995). Collective efficiency: growth path for samll-scale industry. Journal of development studies, 34(4), 529-566.

Schmitz, H. (1997).Collective Efficiency and Increasing Returns. Cambridge Journal of Economics, 23.4:465-483.

Schmitz, H. (1999). Collective efficiency: growth path for small-scale industry. Journal of development studies, 31(9), 465-483.

Schmitz, H., \& Nadvi, K. (1999). Clustering and Industrialization: Introduction. World Development, 27(9), 1503-1514.

Wang, J. C. (2006). China's consumer-goods manufacturing clusters, with reference to Wenzhou footwear cluster. Innovation : management, policy\& practice, 8(1-2), 160-117.

Weijland, H. (1994), "Trade networks for flexible rural industry", in Pedersen, P.O., Sverrison, A., van Dijk, M.P. (Eds),Flexible Specialisation. Dynamics of Small-Scale Industries in the South, Intermediate Technology Publications, London .

Whitford, J. (2001). The decline of a model? Challenge and response in the Italian industrial districts. Economy \& Society, 30(1), 38-65.

Table. Forms of joint action in clusters

\begin{tabular}{|c|c|c|}
\hline & Bilateral & Multilateral \\
\hline Horizontal & e.g. Sharing Equipment & e.g. Sectoral Association \\
\hline Vertical & $\begin{array}{c}\text { e.g. Producer and user } \\
\text { improving components }\end{array}$ & $\begin{array}{c}\text { e.g. Alliance across value } \\
\text { added chain }\end{array}$ \\
\hline
\end{tabular}

Source: Schmitz (1995). 